\title{
Millk of calcium: A rare manifestation of juvenile dermatomyositis
}

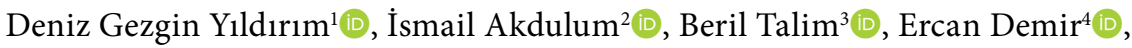 \\ Necla Buyan ${ }^{1}$ (D), Sevcan A. Bakkaloğlu1 ${ }^{1}$ \\ ${ }^{1}$ Department of Pediatrics, Division of Pediatric Rheumatology, Gazi University, Faculty of Medicine, Ankara, Turkey \\ ${ }^{2}$ Department of Radiology, Division of Pediatric Radiology, Gazi University, Faculty of Medicine, Ankara, Turkey \\ ${ }^{3}$ Department of Pathology Unit, Hacettepe University, Faculty of Medicine, Ankara, Turkey \\ ${ }^{4}$ Department of Pediatrics, Division of Pediatric Neurology, Gazi University, Faculty of Medicine, Ankara, Turkey
}

Juvenile dermatomyositis (JDM) is a chronic autoimmune disease characterized by systemic capillary vasculopathy, which leads to proximal myopathy and pathognomonic skin rashes., ${ }^{1,2}$ Herein, we report a patient who was diagnosed with JDM complicated with an extremely rare event, known as 'milk of calcium' formation.

A 3.5-year-old girl was referred to our clinic with complaints of muscle weakness, rash on her cheeks, periorbital area and extensor surface of her hands for two years. Physical examination revealed heliotrope rash, Gottron's papules and calcinosis on the right lateral thigh. Mildly elevated acute phase reactants and muscle enzyme levels were detected. Anti-nuclear antibody and rheumatoid factor were negative, while anti-melanoma differentiation-associated gene 5 antibody was positive. The lower extremity magnetic resonance imaging (MRI) showed myositis and electromyography showed diffuse proximal myopathy. In deltoid muscle biopsy, the major histocompatibility class-I expression was shown to be increased, which is compatible with early histological finding of JDM. MRI and ultrasonography (USG) showed a large collection area containing calcified liquid material, 'milk of calcium', in the right lower limb muscle groups (Figure 1). The diagnosis of JDM was confirmed according to Bohan and Peter criteria. ${ }^{3}$ The collection was drained under USG guidance, and high calcium and phosphorus values were detected in the aspiration material. $2 \mathrm{mg} / \mathrm{kg} /$ day oral prednisolone, nine doses of monthly $2 \mathrm{~g} / \mathrm{kg}$ intravenous immunoglobulin (IVIG), and subcutaneously $15 \mathrm{mg} / \mathrm{m}^{2} /$ week methotrexate (MTX) were prescribed. Corticosteroid therapy was gradually tapered after the first month of therapy and continued as a low dose. The muscle weakness disappeared, but the milk of calcium did not regress. Four doses of intravenous pamidronate $(1 \mathrm{mg} / \mathrm{kg})$ three months apart and six doses of monthly $500 \mathrm{mg} / \mathrm{m}^{2}$ cyclophosphamide were added to the therapy. At the one-year follow-up, a prominent regression in milk of calcium collection was observed. A written informed consent was obtained from the patient's parents.

Calcinosis is one of the most substantial sequelae of JDM, seen in $30-70 \%$ of patients. It is associated with delay in diagnosis and treatment,

Received: May 06, 2020 Accepted: June 25, 2020 Published online: December 10, 2020

Correspondence: Deniz Gezgin Yıldırım, MD. Gazi Üniversitesi Tıp Fakültesi Çocuk Romatolojisi Bilim Dalı, 06560 Yenimahalle, Ankara, Türkiye. Tel: +90 505 - 4343190 e-mail: gezgindeniz@gmail.com 

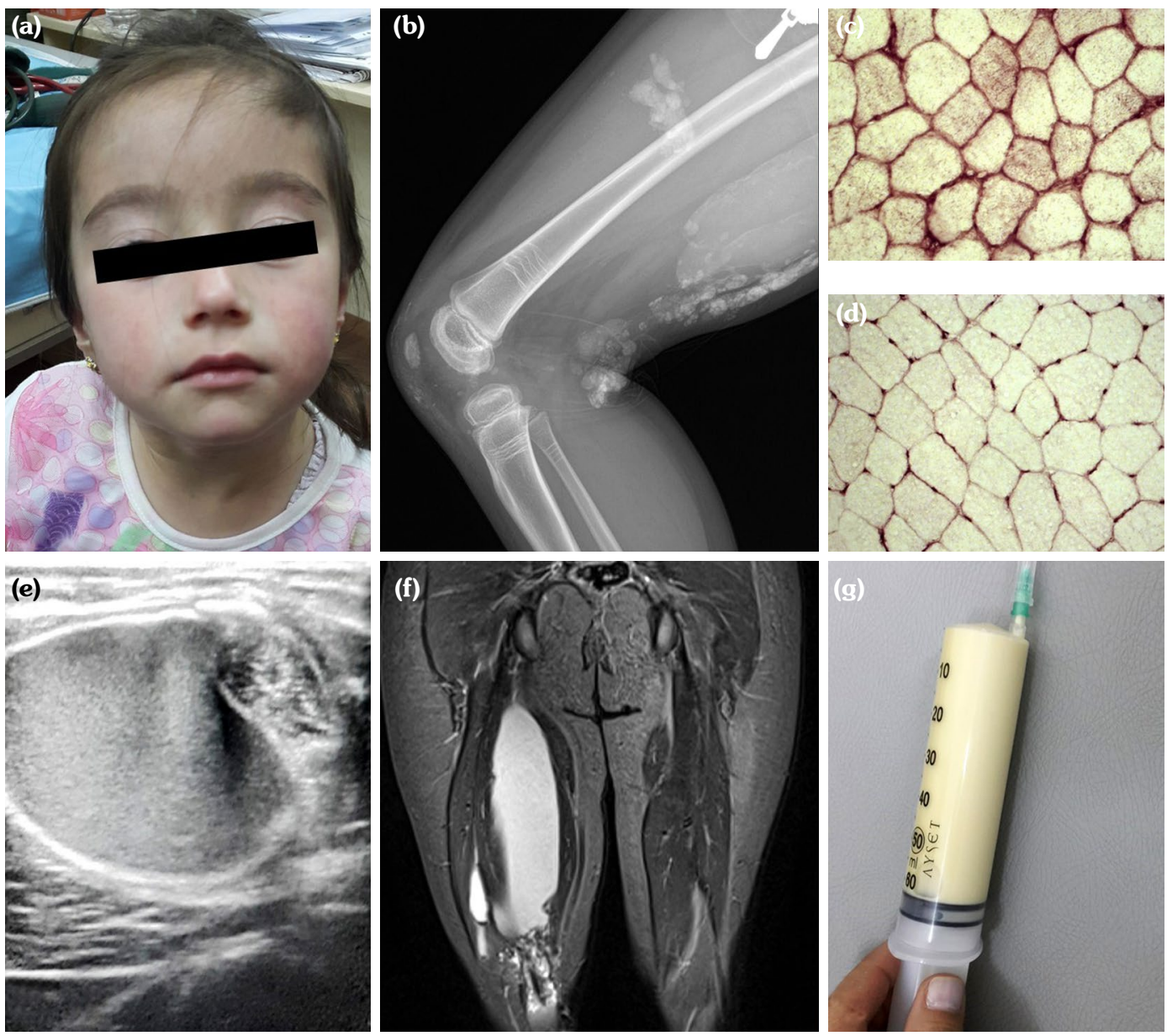

Figure 1. Radiographic and histopathological images and appearance of patient. (a) Heliotrope rash. (b) Widespread calcinosis at right lower extremity. (c) Increased major histocompatibility class-I expression in muscle biopsy. (d) Normal muscle biopsy. (e-g) Milk of calcium formation in ultrasonography, magnetic resonance imaging and drainage material.

inadequate therapy, organ involvement, joint contractures and lipodystrophy. ${ }^{2,4}$ Tissue injury resulting from trauma or inflammation triggers the deposition of insoluble calcium salts in subcutaneous tissues, muscles and skin. ${ }^{5,6}$ Soft tissue swelling in JDM patients should raise a suspicion about the development of milk of calcium. ${ }^{7}$ This lesion can be determined by MRI and USG, and differentiated from infection and hemorrhage. ${ }^{8,9}$ Mukamel et al. ${ }^{10}$ reported two children with JDM who had presented with milk of calcium. Drainage material showed increased levels of pro-inflammatory cytokines and alendronate showed a beneficial effect on the treatment of this condition. Calcinosis treatment remains controversial, and multiple treatment strategies, such as calcium channel blockers, bisphosphonates, probenecid, aluminum hydroxide, thalidomide, colchicine, intralesional steroids, rituximab, infliximab and IVIG have been attempted with variable success rates. ${ }^{4,5,11,12}$ In our case, the calcinosis was resistant to steroids, MTX and IVIG treatments, but cyclophosphamide and pamidronate therapies showed a beneficial effect leading to the regression of milk of calcium.

Juvenile dermatomyositis may be confronted with various clinical findings apart from the typical cutaneous changes. A longer diagnosis lag time and treatment delay in JDM could lead to severe complications which are resistant to conventional therapies. Milk of calcium is an extremely rare but one of the most devastating complications of JDM 
which may gain benefit from cyclophosphamide and pamidronate therapies.

\section{Declaration of conflicting interests}

The authors declared no conflicts of interest with respect to the authorship and/or publication of this article.

\section{Funding}

The authors received no financial support for the research and/or authorship of this article.

\section{REFERENCES}

1. Batthish M, Feldman BM. Juvenile dermatomyositis. Curr Rheumatol Rep 2011;13:216-24.

2. Barut K, Aydin PO, Adrovic A, Sahin S, Kasapcopur O. Juvenile dermatomyositis: a tertiary center experience. Clin Rheumatol 2017;36:361-6.

3. Bohan A, Peter JB. Polymyositis and dermatomyositis (first of two parts). N Engl J Med 1975;292:344-7.

4. Orandi AB, Dharnidharka VR, Al-Hammadi N, Baszis KW; CARRA Legacy Registry Investigators. Clinical phenotypes and biologic treatment use in juvenile dermatomyositis-associated calcinosis. Pediatr Rheumatol Online J 2018;16:84.

5. Li J, Zhou Z. Calcinosis in juvenile dermatomyositis. N Engl J Med 2019;381:e31.

6. Boulman N, Slobodin G, Rozenbaum M, Rosner I. Calcinosis in rheumatic diseases. Semin Arthritis Rheum 2005;34:805-12.

7. de Castro TC, Guarniero R, Giacomin MF, Meneghin MB, Martins GB, Lotufo Sde A. "Milk of calcium": a rare presentation of calcinosis. Rev Bras Reumatol 2014;54:65-7.

8. Samson C, Soulen RL, Gursel E. Milk of calcium fluid collections in juvenile dermatomyositis: MR characteristics. Pediatr Radiol 2000;30:28-9.

9. Hesla RB, Karlson LK, McCauley RG. Milk of calcium fluid collection in dermatomyositis: ultrasound findings. Pediatr Radiol 1990;20:344-6.

10. Mukamel M, Horev G, Mimouni M. New insight into calcinosis of juvenile dermatomyositis: a study of composition and treatment. J Pediatr 2001;138:763-6.

11. Hoeltzel MF, Oberle EJ, Robinson AB, Agarwal A, Rider LG. The presentation, assessment, pathogenesis, and treatment of calcinosis in juvenile dermatomyositis. Curr Rheumatol Rep 2014;16:467.

12. Tayfur AC, Topaloglu R, Gulhan B, Bilginer Y. Bisphosphonates in juvenile dermatomyositis with dystrophic calcinosis. Mod Rheumatol 2015;25:615-20. 